\title{
ИССЛЕДОВАНИЕ ВЛИЯНИЯ СВЧ-ИЗЛУЧЕНИЯ НА СВОЙСТВА ПРОДУКТОВ ПИТАНИЯ РАСТИТЕЛЬНОГО ПРОИСХОЖДЕНИЯ МЕТОДАМИ ЭПР И ИК-СПЕКТРОСКОПИИ
}

\author{
(C) Р.Г. Яхин ${ }^{1}$, Н.А. Самигуллина ${ }^{2}$, Э.М. Ягуно ${ }^{I^{*}}$, Р.Р. Яхин ${ }^{3}$ \\ ${ }^{1}$ Казанский государственный архитектурно-строительный университет, \\ ул. Зеленая, 1, Казань, 420043 (Россия), e-mail: yagund1962@mail.ru \\ ${ }^{2}$ Татаро-английская гимназия №16, ул. Дубравная, 51a, Казань, 420139 \\ (Россия) \\ ${ }^{3}$ Межрегиональный клинико-диагностический центр, ул. Карбышева, 12а, \\ Казань, 420056 (Россия)
}

Технический прогресс, наряду с несомненными достижениями, привносит в экологию питания существенные проблемы. Элетромагнитные поля СВЧ-диапазона являются одними из существенных загрязнителей как окружающей среды в целом, так и продуктов питания в частности. Под воздействием СВЧ-излучения с высокой плотностью потока энергии в продуктах питания возможно образование групп с неспаренными электронами (свободных радикалов), являющихся одной из причин преждевременного старения организма человека.

В данной работе методами ЭПР и Фурье ИК-спектроскопии в средней области проведен качественный анализ процессов, происходящих в ряде продуктов питания растительного происхождения при воздействии на них различных доз СВЧ-излучения. Методом ЭПР установлено, что исходные материалы содержат незначительное количество парамагнитных центров (свободных радикалов), однако под воздействием СВЧ-излучения их количество увеличивается пропорционально времени и (или) мощности излучения. В ИК-спектрах СВЧ-обработка проявляется в уменьшении интенсивности полосы поглощения $v(\mathrm{OH})$, что связано, по-видимому, с потерей молекулярной воды образцами при нагреве и ростом интенсивности полосы $v(\mathrm{C}=\mathrm{O})$, что может быть объяснено образованием некоторого количества сложноэфирных и кетонных групп в системах в результате термоокислительной деструкции (пиролиза) либо переходом органических молекул в перекислое состояние под воздействием свободных радикалов.

Ключевые слова: продукты питания растительного происхождения, свободные радикалы, СВЧ-излучение, ЭПР, метод Фурье ИК-спектроскопии.

\section{Введение}

Как известно, качество продуктов питания является неотъемлемой составляющей существования, благополучия и качества жизни. Пища, наряду с важнейшими нутриентами, содержит большое количество различных по структуре химических соединений, представляющих потенциальную опасность для здоровья человека. Ими могут быть собственно компоненты пищевых продуктов, продукты их биотрансформации и загрязнители окружающей среды, попадающие в пищу в результате накопления в трофических цепях, а также свободные радикалы. Технический прогресс, наряду с несомненными достижениями, привносит проблемы в экологию питания. Электромагнитные поля являются одними из существенных загрязнителей

Рашит Гарафутдинович Яхин - заведующий кафедрой физики, электротехники и автоматики,

e-mail: yagund1962@mail.ru

Нурзиля Альбертовна Самигуллина - учитель химии, e-mail: yagund1962@mail.ru

Ягунд Эдуард Михайлович - доцент кафедры физики, электротехники и автоматики,

e-mail: yagund1962@mail.ru

Рустем Рашитович Яхин - врач-хирург,

e-mail: yagund1962@mail.ru как окружающей среды в целом, так и продуктов питания в частности. В литературе в последнее десятилетие даже появился соответствующий термин - «электромагнитный смог». СВЧ-излучение с очень высокой плотностью потока энергии способно вызывать процессы деструкции высокомолекулярных органических молекул (в частности, денатурацию белков при нагреве), приводящие к образованию

\footnotetext{
* Автор, с которым следует вести переписку.
} 
групп с неспаренными электронами, т.е. свободных радикалов, являющихся одной из причин преждевременного старения организма человека [1].

Среди современных методов анализа пищевых продуктов все большее распространение приобретает спектроскопия, позволяющая получить наиболее полную информацию о важнейших свойствах продукта. Спектральные методы исследования основаны на использовании явления поглощения (или испускания) электромагнитного излучения атомами или молекулами определенного вещества [2]. Для изучения изменений, происходящих в веществе при их СВЧ-облучении, нами были применены методы электронного парамагнитного резонанса (ЭПР) и Фурье ИК-спектроскопии (ИКС).

Метод ЭПР позволяет получить важную информацию о магнитных свойствах вещества, а так как магнитные свойства вещества находятся в прямой зависимости от его молекулярной структуры, то метод ЭПР является весьма перспективным для изучения строения веществ. При изучении свободных радикалов метод ЭПР незаменим.

Инфракрасная спектроскопия позволяет получать достаточно полную информацию о строении и составе органических веществ. ИК-спектроскопия позволяет идентифицировать почти все функциональные группы, исследовать меж- и внутримолекулярные взаимодействия молекул и в настоящее время с успехом применяется для качественного и количественного исследования пищевых продуктов [3].

\section{Методика эксперимента}

Для проведения исследований применялся комплекс ЭПР-аппаратуры, включающий спектрометр ЭПР-10 МИНИ (Санкт-Петербург) и персональный компьютер. Исследования проводились при комнатной температуре с образцами пищевых продуктов растительного происхождения. В качестве образцов использовались чай черный из пакетиков, чай черный листовой, чай зеленый из пакетиков, чай зеленый листовой, кофе молотый, кофе в зернах, поскольку чай и кофе - это повседневные напитки многих людей. Каждый из перечисленных пищевых продуктов сначала подвергался воздействию СВЧ-излучения в установке, описанной в [4], продолжительностью 5, 10, 15, 20, 25 и 30 мин. Мощность СВЧ-нагрева составляла 750 Вт. Затем образцы были измельчены, разделены на фракции по размерам, взвешены на аналитических весах и засыпаны в кварцевые ампулы, не дающие паразитного сигнала. Ампулы первоначально проверялись на спектрометре без образцов, и из них отбирались аналитические с наименьшим фоновым сигналом. Измельчение проводилось вручную в агатовой ступке. Фракции для анализа 0,5-2 мм отбирались с помощью сит из нержавеющей стали, не загрязняющей парамагнитными примесями просеиваемый образец. После этого проводился эксперимент по выявлению сигнала ЭПР от вышеперечисленных образцов с различными временами СВЧ-экспозиции [4].

Регистрация ИК-спектров образцов производилась на Фурье ИК-спектрофотометре фирмы PerkinElmer, модель Spectrum 65, с помощью приставки НПВО Miracle ATR (кристалл ZnSe) в области 4000$650 \mathrm{~cm}^{-1}$, как правило, при 20 сканах. Запись и вычитание фонового спектра производились автоматически. Контрольный и подвегнутые СВЧ-обработке образцы измельчались в вибромельнице в течение 5 мин до частиц микронного размера, после чего образовавшийся порошок прижимался к кристаллу НПВО специальным прижимом, входящим в комплект приставки. После регистрации автоматически осуществлялись НПВО-коррекция и сохранение спектра. ИК-спектры образцов, подвергнутых СВЧ-облучению, сравнивались со спектром контрольного образца, не подвергавшегося обработке. При этом изменение интенсивности характеристических пиков оценивалось по методике [5] относительно полосы внутреннего стандарта, за который был принят пик на частоте около $820 \mathrm{~cm}^{-1}$, соответствующий валентным колебаниям глюкопиранозных колец целлюлозы.

\section{Обсуждение результатов}

При исследовании перечисленных выше продуктов методом ЭПР для необработанных образцов во всех случаях наблюдались исходные сигналы (рис. 1).

После облучения в образцах появляются радиационные сигналы разной формы и амплитуды при одинаковой дозе облучения и по разному «наложенные» на исходный сигнал, причем интенсивность сигнала возрастала пропорционально времени облучения. Это свидетельствовало об увеличении концентрации свободных радикалов в образцах. На рисунке 2 приведены графики зависимости интенсивности сигнала ЭПР от времени облучения образцов. 


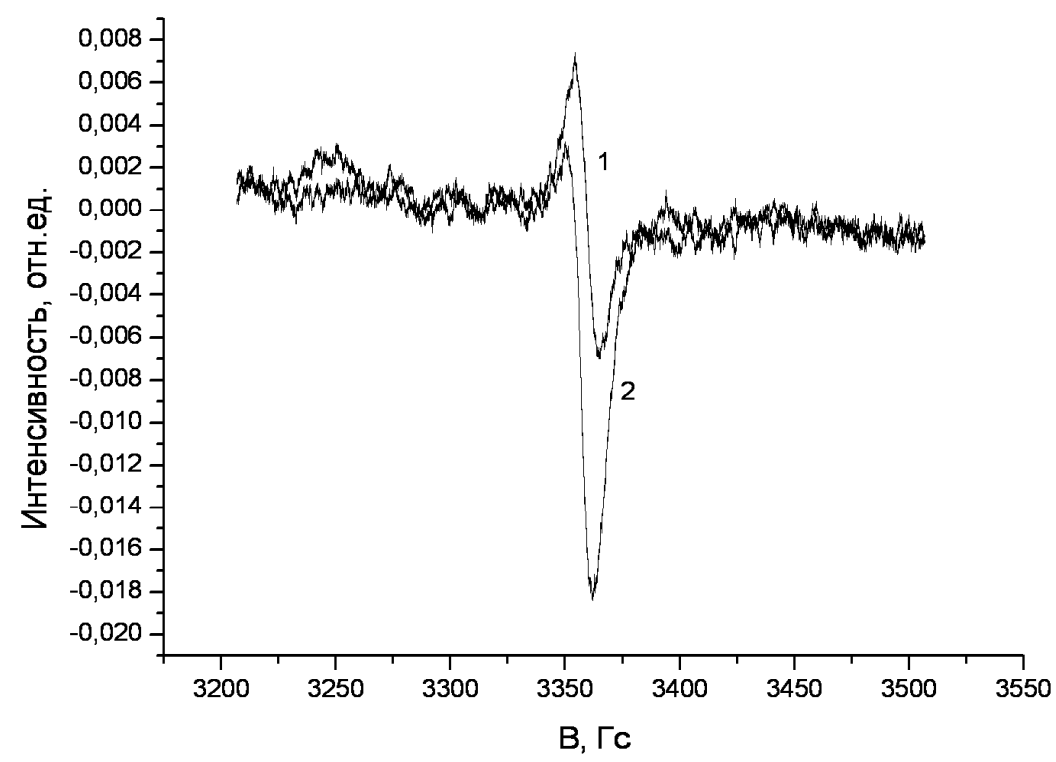

Рис. 1. Форма ЭПР-сигнала для необлученного образца черного байхового чая (1) и образца, подвергнутого СВЧ-обработке мощностью 750 Вт в течение 30 мин (2)
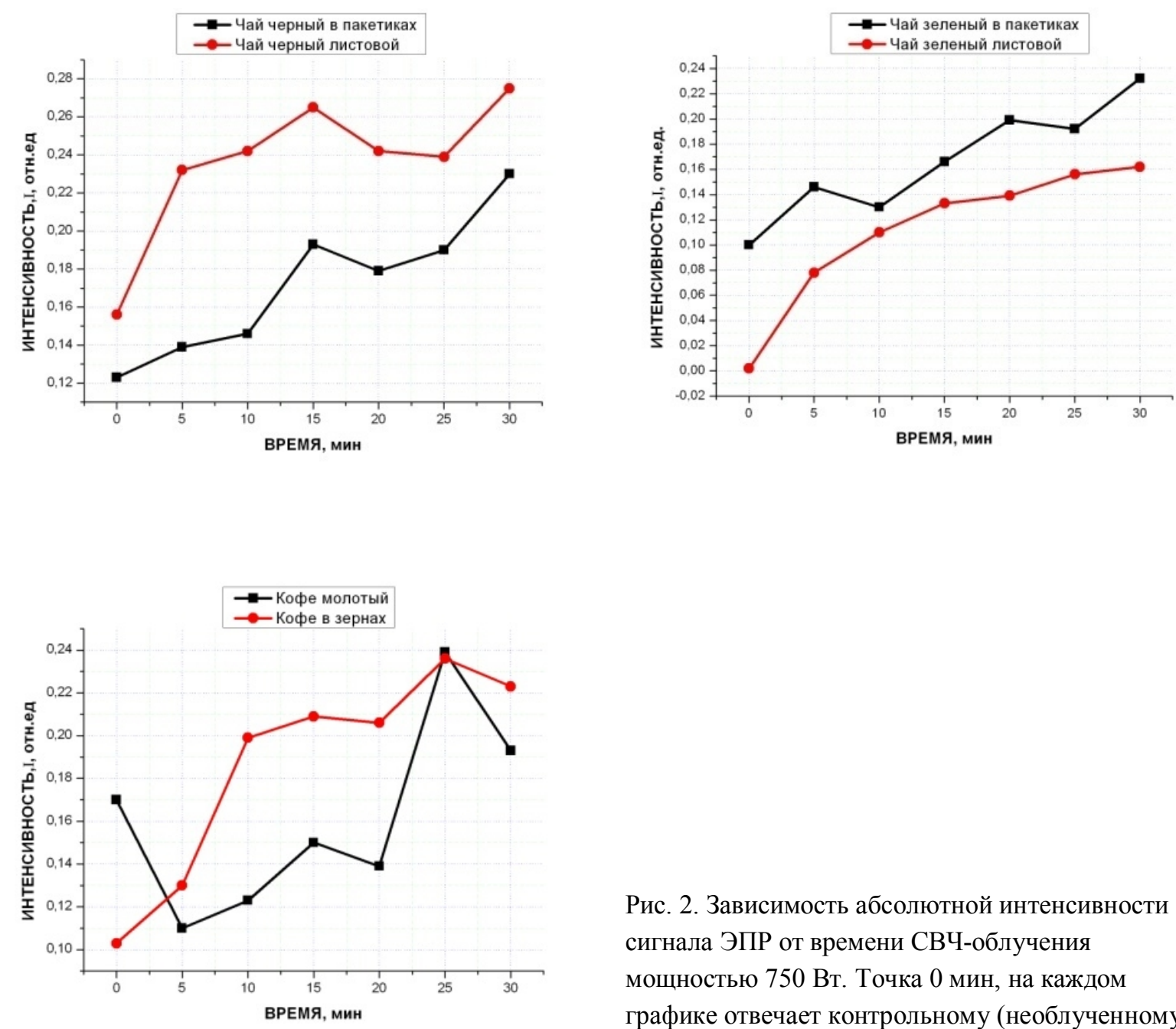

Рис. 2. Зависимость абсолютной интенсивности I сигнала ЭПР от времени СВЧ-облучения мощностью 750 Вт. Точка 0 мин, на каждом графике отвечает контрольному (необлученному) образцу 
Если исходить из полученных данных, то можно предположить, что исходные материалы изначально содержали незначительное количество свободных радикалов. Под воздействием электромагнитного СВЧ-излучения в образцах увеличивается количество такого рода парамагнитных центров или образуются новые. Концентрация парамагнитных центров, или свободных радикалов в эксперименте была прямо пропорциональна времени и (или) мощности электромагнитного воздействия.

Прежде чем переходить к описанию результатов, полученных методом ИКС, необходимо отметить, что все изученные образцы созданы на основе растительного сырья, и, соответственно, основу молекулярной структуры каждого из них составляет целлюлоза. Это, как известно, полисахарид, высокомолекулярный полимер растительного происхождения, главная составляющая клеточных стенок высших растений. Макромолекула целлюлозы состоит из шестичленных углеродно-кислородных, так называемых пиранозных циклов, соединенных ацетальными мостиками [6]. Наиболее полно высокомолекулярные углеводы растительной природы изучены методом ИКС в монографиях Р.Г. Жбанкова [7, 8], а также в ряде других работ [9-12].

Анализ спектров показывает (табл.), что в них присутствуют все пики, отвечающие колебаниям функциональных групп, входящих в состав целлюлозы, а именно: в области $1034 \mathrm{~cm}^{-1}$ (наиболее интенсивная полоса, отвечающая смешанным валентным и деформационным колебаниям связей С-O-C и C-C скелета макромолекулы и пиранозных циклов, расщепленная на ряд более слабых полос), дублет 2919 и $2850 \mathrm{~cm}^{-1}$, отвечающий колебаниям $\mathrm{CH}_{2}$ - и $\mathrm{CH}_{3}$-групп, широкий пик с максимумом $3281 \mathrm{~cm}^{-1}$, отвечающий валентным связанных водородными связями гидроксильных групп, пики поглощения карбонильных групп в области $1730-1740 \mathrm{~cm}^{-1}$, и ряд других.

Относительно полосы ОН-групп в области $3281 \mathrm{~cm}^{-1}$ необходимо отметить, что она регистрирует как колебания гидроксилов, интегрированных в шестичленные циклы целлюлозы, так и колебания молекулярной воды $\mathrm{H}_{2} \mathrm{O}$, адсорбированной образцами, причем эти колебания накладываются друг на друга. Адсорбированная образцами вода дает также полосу в области 1620-1640 см-1, причем там проявляются деформационные колебания молекул $\mathrm{H}_{2} \mathrm{O}$, наложенные на полосы связей $\mathrm{C}=\mathrm{C}$ ароматических ядер и карбоксильных групп [12].

На рисунке 3 приведены ИК-спектры образцов исходного (кривая 1) и обработанного СВЧ в течение 30 мин (кривая 2) черного чая.

Сравнение спектров показывает, что обработка в СВЧ-печи не приводит к заметному изменению ИК-спектра образца. Отметим, что незначительно уменьшается по интенсивности полоса $v(\mathrm{OH})$ при $3281 \mathrm{~cm}^{-1}$ (уменьшение интегральной интенсивности с учетом внутреннего стандарта составляет около $16 \%$ ), что можно объяснить потерей молекулярной воды образцом вследствие разогрева. Изменения положения максимума этого пика не происходит. Это свидетельствует, по-видимому, о том, что структура водородных связей не претерпевает изменений. Для зеленого чая результаты были аналогичны.

ИК-спектр молотых кофейных зерен несколько отличается от спектра черного и зеленого чая. Прежде всего необходимо отметить гораздо большую, чем у чая, интенсивность полос 2927 и 2854 см ${ }^{-1}$ мети-

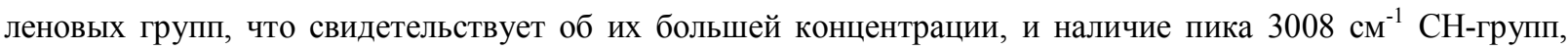
входящих в структуру ароматических ядер. Кроме того, полоса поглощения карбонильных групп, которая в спектрах чая имеет вид слабо выраженного плеча при $1734 \mathrm{~cm}^{-1}$, в спектрах кофе проявляется в виде интенсивного пика на частоте $1742 \mathrm{~cm}^{-1}$ (рис. 4). Максимум поглощения полосы $v(\mathrm{OH})$ смещен в сторону высоких частот к $3314 \mathrm{~cm}^{-1}$.

Наличие функциональных групп в образцах растительных продуктов, см$^{-1}$

\begin{tabular}{|c|c|c|c|c|}
\hline \multirow{2}{*}{$\begin{array}{c}\text { Образцы растительных } \\
\text { продуктов }\end{array}$} & \multicolumn{4}{|c|}{ Функциональные группы } \\
\hline & $-\mathrm{C}-\mathrm{O}-\mathrm{C}-, \mathrm{C}-\mathrm{C}$ & $\mathrm{CH}, \mathrm{CH}_{2}, \mathrm{CH}_{3}$ & $-\mathrm{OH}$ & $-\mathrm{C}=\mathrm{O}$ \\
\hline Черный байховый чай & $\begin{array}{c}1144,1031,1092, \\
875,820\end{array}$ & 2850,2919 & 3281 & 1734 (плечо) \\
\hline Зеленый чай & $\begin{array}{c}1146,1031,1096 \\
877,821\end{array}$ & 2851,2919 & 3282 & 1732 (плечо) \\
\hline Кофе натуральный молотый & $\begin{array}{c}1155,1034,1027, \\
869,820\end{array}$ & $2853,2923,3008$ & 3314 & 1742 \\
\hline Кофе в зернах & $\begin{array}{c}1186,1055,1222 \\
873,816\end{array}$ & $2856,2928,3008$ & 3333 & 1733 \\
\hline
\end{tabular}




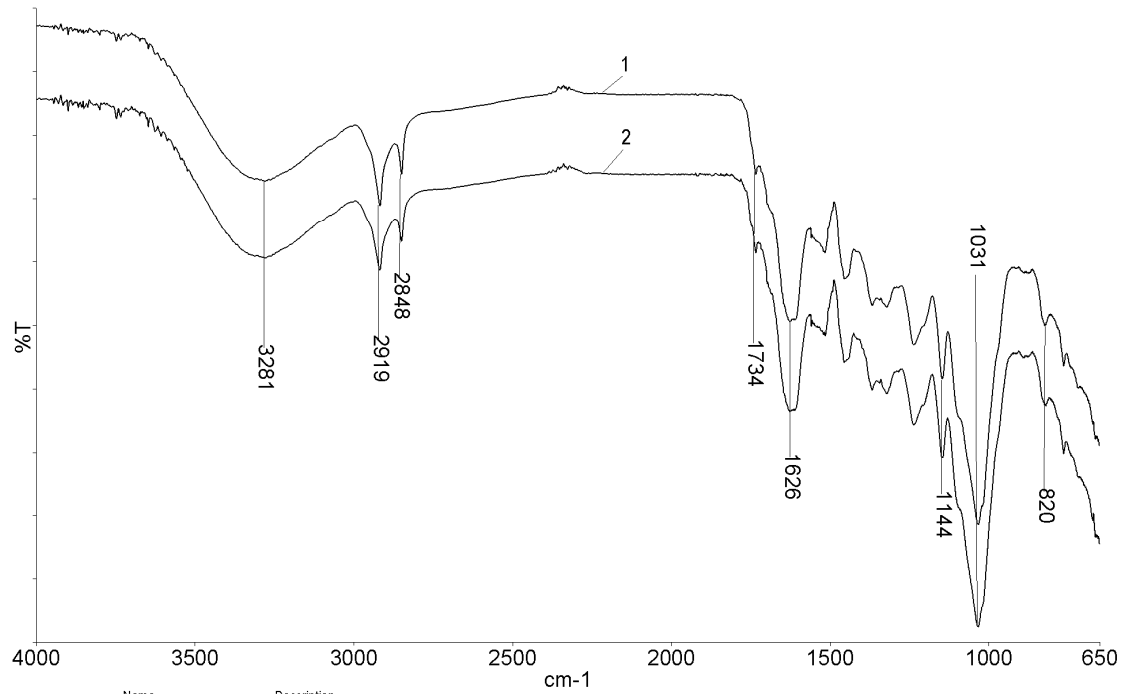

Рис. 3. ИК-спектры исходного (1) и обработанного СВЧ (2) черного байхового чая

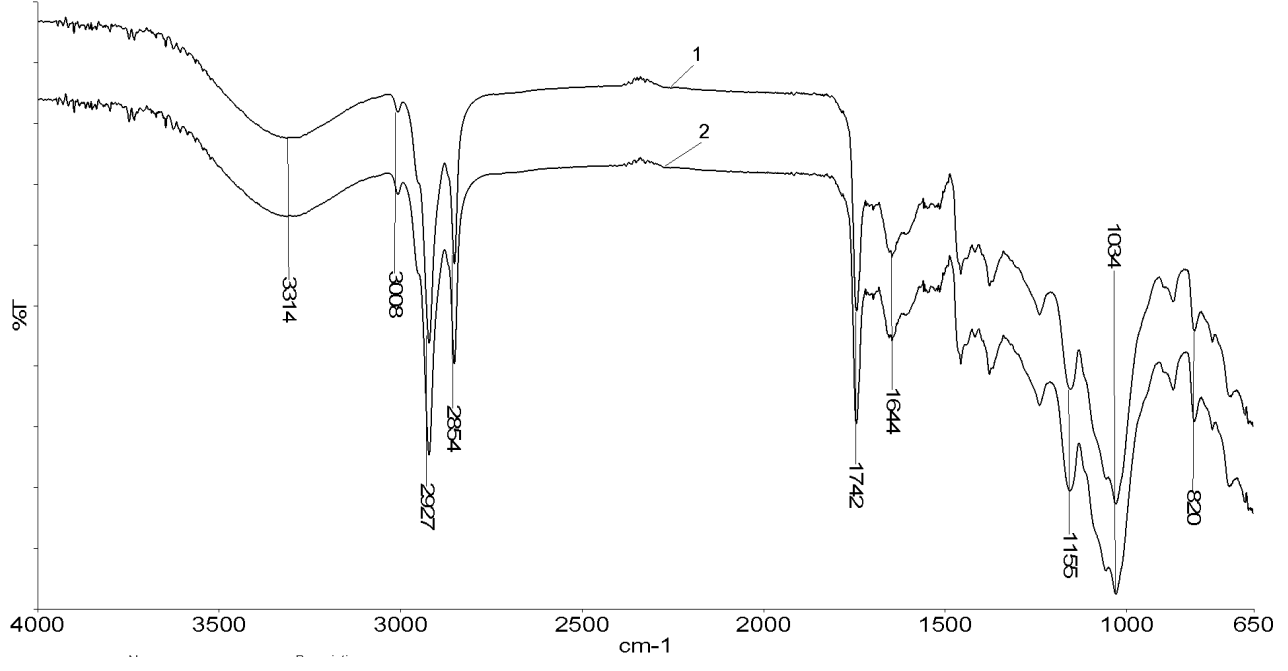

Рис. 4. ИК-спектры исходного (1) и обработанного СВЧ (2) молотого кофе

Обработка кофе СВЧ-излучением, как и в случае черного и зеленого чая, не приводит к заметному изменению ИК-спектров. Необходимо отметить лишь, как и в случае чая, незначительное уменьшение интенсивности полосы $v(\mathrm{OH})$ при 3314 см-1 (около 14\%), обусловленное потерей молекулярной воды при подсушивании, и более заметное увеличение интенсивности полосы $v(\mathrm{C}=\mathrm{O})$ на частоте $1742 \mathrm{cm-1}$, которое при максимальном времени обработки составляет порядка $20 \%$ (при неизменной интенсивности полосы внутреннего стандарта 820 см-1). Вероятно, такое увеличение интенсивности карбонильной полосы обусловлено процессами термоокислительной деструкции органических молекул (пиролиза) либо связано с ростом концентрации парамагнитных центров в образцах, регистрируемых также методом ЭПР, так как известно, что переход органических продуктов в перекислое состояние под воздействием оксидантов сопровождается образованием значительного количества сложноэфирных и кетонных групп [13].

Исходя из выше изложенного можно предположить, что исходные материалы изначально содержали незначительное количество свободных радикалов. Под воздействием электромагнитного СВЧ-излучения в образцах увеличивается количество парамагнитных центров или образуются новые, как это показано методом ЭПР. Концентрация парамагнитных центров (или свободных радикалов) прямо пропорционально времени и (или) мощности электромагнитного воздействия. Обработка СВЧ-излучением незначительно отражается на ИК-спектрах образцов. Необходимо отметить лишь незначительную потерю молекулярной воды образцами и рост интенсивности полосы карбонильных групп в образцах кофе, обусловленный, повидимому, процессами пиролиза при разогреве либо с ростом концентрации свободных радикалов в образцах, установленный методом ЭПР. 


\section{Выводы}

1. Методом ЭПР исследованы процессы, происходящие в ряде образцов продуктов питания растительного происхождения при воздействии на них различных доз электромагнитного СВЧ-излучения. Показано, что СВЧ-обработка приводит к росту содержания парамагнитных центров (свободных радикалов) в образцах, причем их концентрация пропорциональна времени и (или) мощности излучения.

2. Методом Фурье ИК-спектроскопии в средней области проведен качественный анализ изменений в спектрах образцов при воздействии на них различных доз СВЧ-излучения. Показано, что обработка образцов приводит к некоторому уменьшению содержания влаги в образцах чая и кофе. Для образцов кофе установлено увеличение интенсивности полосы поглощения карбонильных групп, что может быть объяснено процессами термоокислительной деструкции либо переходом органических молекул в перекислое состояние под воздействием свободных радикалов.

\section{Список литературь}

1. Кривошеин Д.А., Муравей Л.А., Роева Н.Н. Экология и безопасность жизнедеятельности: учебное пособие для вузов. М., 2000. 447 с.

2. Подлегаева Т.В., Просеков А.Ю. Методы исследования свойств сырья и продуктов питания: учебное пособие. Кемерово, 2004. $101 \mathrm{c}$

3. Моренко В.В. Хижан Е.И., Хижан А.И., Николаевский А.Н. Использование ближней инфракрасной спектроскопии для анализа пищевых продуктов // Вестник Донецкого национального университета. Сер. А. 2011 . №2. C. $120-123$.

4. Самигуллина Н.А., Яхин Р.Г., Яхин Р.Р. Влияние СВЧ-облучения на продукты питания растительного происхождения // Инновационная наука. Уфа, 2014. С. 47-50.

5. Котенева И.В., Сидоров В.И., Котлярова И.А. Анализ модифицированной целлюлозы методом ИКспектроскопии // Химия растительного сырья. 2011. №1. С. 21-24.

6. Энциклопедия полимеров. М., 1977. Т.3. С. 853-860.

7. Жбанков Р.Г. Инфракрасные спектры и структура углеводов. Минск, 1972. 298 с.

8. Жбанков Р.Г. Инфракрасные спектры целлюлозы и ее производных. Минск, 1964. 108 с.

9. Мухамадеева Р.М., Жбанков Р.Г., Сопин В.Ф., Марченко Г.Н. Низкочастотная ИК-спектроскопия в исследовании структуры целлюлозы и нитратов целлюлозы // Успехи химии. 1993. Т. 62. №4. С. 351-364.

10. Геньш К.В., Колосов П.В., Базарнова Н.Г. Качественный анализ нитратов целлюлозы методом ИК-Фурьеспектроскопии // Химия растительного сырья. 2010. №1. С. 63-66.

11. Сивчик В.В., Жбанков Р.Г. Исследование колебательных спектров D-глюкозы и ряда моносахаридов // Журнал прикладной спектроскопии. 1978. Т. 28, №6. С. 1038-1045.

12. Гасанова Е.С., Мязин Н.Г., Фоминых Т.О. Изучение системы почва - растение на примере топинамбура методом ИК-спектроскопии // Вестник Воронежского государственного аграрного университета. 2014. №1-2. С. 14-19.

13. Владимиров Ю.А. Свободнорадикальное окисление липидов и физические свойства липидного слоя биологических мембран // Биофизика. 1987. Т. 32. №5. С. 830-844.

Поступило в редакиию 12 апреля 2016 г.

После переработки 31 октября 2016 г. 
Yakhin R.G. ${ }^{1}$,Samigullina N.A ${ }^{2}$. Yagund E.M. ${ }^{1 *}$, Yakhin R.R. ${ }^{3}$ INVESTIGATION OF THE INFLUENCE OF MICROWAVE RADIATION ON THE PROPERTIES OF VEGETABLE FOOD PRODUCTS BY METHODS OF EPR AND IR SPECTROSCOPY

${ }^{1}$ Kazan State University of Architecture and Engineering, ul. Zelenaya, 1, Kazan, 420043 (Russia),

e-mail:yagund1962@mail.ru

${ }^{2}$ Tatar-English Grammar School №16, ul. Dubravnaya, 51a, Kazan, 420139 (Russia).

${ }^{3}$ Interregional Clinical and diagnostic center, ul. Karbisheva, 12a, Kazan, 420056 (Russia).

Technological progress brings to the feeding ecology some significant problems. Eletromagnetic microwave fields are some of the major pollutants as environment in general and food products in particular. Under the influence of microwave radiation with a high energy density in food products, the formation of groups with unpaired electrons (free radicals) possible, which are one of the causes of premature aging of the human organism.

In this work by the methods of EPR and Fourier IR spectroscopy in the middle area carried out a qualitative analysis of the processes taking place in a number of vegetable food products when exposed to different doses of microwave radiation. EPR spectroscopy revealed that the starting materials contain a small amount of paramagnetic centers (free radicals), but under the influence of the microwave radiation it increases in proportion of time and (or) the radiation power. The IR spectra is a decrease in the absorption band intensity $v(\mathrm{OH})$, due, apparently, to the loss of molecular water samples during heating and rising band intensity $v(\mathrm{C}=\mathrm{O})$, which may be explained by the formation of significant amounts of ester and ketone groups in the systems as a result of thermal oxidative degradation (pyrolysis) or organic molecules in the transition state under the influence of superoxide free radicals.

Keywords: vegetable food products, microwave radiation, free radicals, EPR, FTIR Method.

\section{References}

1. Krivoshein D.A., Muravei L.A., Roeva N.N. Ekologiia i bezopasnost' zhiznedeiatel'nosti: uchebnoe posobie dlia vuzov. [Ecology and life safety: a textbook for high schools]. Moscow, 2000, 447 p. (in Russ.).

2. Podlegaeva T.V., Prosekov A.Iu. Metody issledovaniia svoistv syr'ia i produktov pitaniia: uchebnoe posobie. [Methods of study properties of raw materials and food: a training manual]. Kemerovo, 2004, 101 p. (in Russ.).

3. Morenko V.V. Khizhan E.I., Khizhan A.I., Nikolaevskii A.N. Vestnik Donetskogo natsional'nogo universiteta. Ser. A, 2011, no. 2, pp. 120-123. (in Russ.).

4. Samigullina N.A., Iakhin R.G., Iakhin R.R. Innovatsionnaia nauka. [Innovative science]. Ufa, 2014, pp. 47-50. (in Russ.).

5. Koteneva I.V., Sidorov V.I., Kotliarova I.A. Khimiia rastitel'nogo syr'ia, 2011, no. 1, pp. 21-24. (in Russ.).

6. Entsiklopediia polimerov. [Encyclopedia of polymer]. Moscow, 1977, vol. 3, pp. 853-860. (in Russ.).

7. Zhbankov R.G. Infrakrasnye spektry i struktura uglevodov. [Infrared spectra and structure of carbohydrates]. Minsk, 1972, 298 p. (in Russ.).

8. Zhbankov R.G. Infrakrasnye spektry tselliulozy i ee proizvodnykh. [Infrared spectra of cellulose and its derivatives]. Minsk, 1964, 108 p. (in Russ.).

9. Mukhamadeeva R.M., Zhbankov R.G., Sopin V.F., Marchenko G.N. Uspekhi khimii, 1993, vol. 62, no. 4, pp. 351364. (in Russ.).

10. Gen'sh K.V., Kolosov P.V., Bazarnova N.G. Khimiia rastitel'nogo syr'ia, 2010, no. 1, pp. 63-66. (in Russ.).

11. Sivchik V.V., Zhbankov R.G. Zhurnal prikladnoi spektroskopii, 1978, vol. 28, no. 6, pp. 1038-1045. (in Russ.).

12. Gasanova E.S., Miazin N.G., Fominykh T.O. Vestnik voronezhskogo gosudarstvennogo agrarnogo universiteta, 2014, no. 1-2, pp. 14-19. (in Russ.).

13. Vladimirov Iu.A. Biofizika, 1987, vol. 32, no. 5, pp. 830-844. (in Russ.).

\footnotetext{
* Corresponding author.
} 
